\title{
Occurrence characteristics of ionospheric irregularities over Indian low-latitude region Varanasi during ascending phase of solar cycle 24
}

\author{
Vishnu S. Rathore ${ }^{1}$, Sanjay Kumar ${ }^{1}$ and A. K. Singh ${ }^{1, *}$ \\ ${ }^{1}$ Department of Physics, Institute of Science, Banaras Hindu University, Varanasi, India.
}

\author{
Article history \\ Received May 12, 2017; accepted February 7, 2018. \\ Subject classification: \\ Ionospheric irregularities; GPS; Scintillations; Solar activity; Low-latitude.
}

\begin{abstract}
Ionospheric irregularities degrade the performance of radio technological system by producing fluctuations in amplitude and phase of signal passing through them, a phenomenon which is known as scintillation. This study presents diurnal and seasonal variations of ionospheric irregularities during ascending phase of solar activity from 2009 to 2014 by using the amplitude scintillation index S4 computed from a dual frequency GPS receiver installed at the low-latitude station of Varanasi (Lat. $25.31^{\circ} \mathrm{N}$, Long. $82.97^{\circ} \mathrm{E}$ ). Scintillation occurrences are found to be higher during nighttime hours (1930-0130 LT), and characterized by an equinoctial maximum throughout the years 2009-2014, except for the peculiar solar minimum year 2009. Gravity wave seed perturbation from lower atmosphere and pre-reversal enhancement (PRE) in zonal electric field have been considered to explain the observed seasonal occurrences, which have been also compared with previous results obtained from observations and model. Influence of solar activity on scintillation occurrence has also been studied, and it was found that there is linear dependence between the solar activity and scintillation occurrence, which is seasonally variable.
\end{abstract}

\section{Introduction}

Ionospheric irregularities are responsible for generating scintillation in electromagnetic signals passing through them. When the electromagnetic signal propagates through the irregular ionosphere, it gets distorted in terms of phase and amplitude, a phenomenon which is known as phase and amplitude scintillation respectively [Aarons et al. 1980, Béniguel et al. 2004]. Severe scintillations can cause problems such as signal power fading, phase cycle slips, and receiver loss of lock and can thus degrade the quality of satellite-based communication and navigation systems. Main source of ionospheric irregularities is structuring and dynamics of ionosphere at equatorial and high latitudes. Equatorial spread $\mathrm{F}$ (ESF) irregularities are mainly generated during the post sunset hours due to plasma interchange instability process driven by the Rayleigh-Taylor (R-T) instability mechanism. This mechanism initiates at the bottom side of ionosphere and causes plasma depletion, which rises to the topside ionosphere in the form of plasma-depleted flux tubes with the nonlinear growth of the instability which gives rise to equatorial plasma bubbles (EPBs) [Groves et al. 1997]. During their evolution, the EPBs generally drift eastward. Secondary instabilities develop at the steepening gradient regions of the rising bubbles in a cascading process leading to hierarchy of irregularities with decreasing scale sizes [Haerendel 1973]

To study the ionospheric irregularities, ionosonde [Rastogi 1980, Abdu 2001], topside sounders [Maruyama and Matuura 1984], scintillation receivers [Basu and Basu 1985, Aarons 1993, Iyer et al. 2006 , Singh et al. 2006], air glow observations [Mendillo and Baumgardner 1982] and satellite measurements [Huang et al. 2011] were used in past years. The different signal wavelengths used in different techniques are susceptible to irregularities of different scale sizes [Kintner et al. 2004]. Therefore, each kind of technique measures ionospheric irregularities of different dimensions. In the beginning, ionospheric scintillations mainly focused on VHF and UHF radio bands. Climatology of scintillation in equatorial and polar regions first reported by Aarons [1982] was performed by organizing the amplitude and phase scintillation of radio beacons observed from 40 to $3000 \mathrm{MHz}$, but nowadays Global Navigation Satellite System (GNSS) (whose working frequencies are $1.57542 \mathrm{GHz}$ and 
$1.22760 \mathrm{GHz}$ ) has become an important tool to study the ionospheric irregularities because of its growing application in civilian and military applications [Rama Rao et al. 2006].

Rama Rao et al. [2006] studied the spatial and temporal characteristics of scintillations during a solar minimum period over the Indian low-latitude regions. It has been noticed that in equinox months the occurrence of scintillation was maximum in the pre-midnight hours, and the intensity of the scintillation activity was stronger around the equatorial ionization anomaly (EIA) region. Using GPS ionospheric scintillation and ROTI measurements, Li et al. [2007] showed a statistical analysis of the ionospheric scintillation and transverse drift velocities of irregularities over Wuhan and Sanya in China. Their results revealed that amplitude scintillations mainly occur from post sunset to near midnight or later. The occurrence rate and intensity of scintillation were enhanced in equinox months and reduced in winter and summer months. Jiao et al. [2014] have made a comparative study of high and low-latitude ionospheric scintillation characteristics using GPS signals. Their results revealed that scintillation is more frequent during nighttime, and almost all low-latitude scintillation events occur within six hours after local sunset.

A number of studies have been done in African, Chinese and Indian low-latitude regions related to ionospheric irregularities during geomagnetic storms and specific solar activity conditions [Straus et al. 2003, Singh et al. 2004, Nishioka et al. 2008, Béniguel et al. 2009, Muella et al. 2009, Spogli et al. 2009, Seemala and Valladares 2011, Alfonsi et al. 2011, Brahmanandam et al. 2012, Seif et al. 2012, Carter et al. 2013, Oron et al. 2013, Deng et al. 2013, Tanna et al. 2013, Spogli et al. 2016]. All above studies of ionospheric irregularities over different regions have been reported so far but study for a recent solar minimum period mainly in equatorial and low-latitude regions is lacking.

In the present paper diurnal and seasonal variation of ionospheric irregularities over a low-latitude region Varanasi (Lat. $25.3^{\circ} \mathrm{N}$, Long. 83.0 ${ }^{\circ} \mathrm{E}$, Magnetic dip Lat. $16.2^{\circ} \mathrm{N}$ ) during an ascending phase of solar activity from January 2009 to December 2014, by using $\mathrm{S}_{4}$ amplitude scintillation index computed from dual frequency GPS receiver has been studied. Effect of solar activity on occurrences of scintillations has also been analyzed. The seasonal occurrences of scintillation have been discussed with reference to observations and modeling results. The method of data analysis is presented in section 2 , results and discus- sion in section 3 and summary of the results in section 4.

\section{Data and Method of Analysis}

In this study, amplitude scintillations recorded over Varanasi using GPS measurements have been used. A dual-frequency GPS receiver NovAtel GSV4004B (L1 of frequency $1.57542 \mathrm{GHz}$ and L2 of frequency $1.22760 \mathrm{GHz}$ ) with choke ring antenna was installed at Varanasi (Lat. 25.31 ${ }^{\circ} \mathrm{N}$, Long. 82.97 $\mathrm{E}$, Magnetic dip Lat. $16.2^{\circ} \mathrm{N}$ ) India. The amplitude scintillations, as indicated by the $\mathrm{S}_{4}$ index, are estimated by the receiver at $60 \mathrm{~s}$ intervals. The amplitude scintillation index $\mathrm{S}_{4}$ is the standard deviation of the received signal intensity (SI) divided by its mean value which, is calculated every 60s using 3000 points of detrended signal intensity measurements. This produces the $S_{4 T}$ index, which includes the effects of ambient noise. The signal intensity is actually received as signal power. Detrended signal intensity is obtained by filtering the intensity measurements in a low-pass filter. $\mathrm{S}_{4}$ and $\mathrm{S}_{4 \mathrm{~T}}$ indices stored in the GSV4004B receiver's data log is defined as follows [Van. Dierendonck and Hua 2001]:

$$
\begin{gathered}
S_{4}=\sqrt{S_{4 T}^{2}-S_{4 N}^{2}} \\
S_{4 T}=\sqrt{\frac{\left\langle S I^{2}>-<S I\right\rangle^{2}}{<S I\rangle^{2}}}
\end{gathered}
$$

where SI shows the signal intensity. $S_{4 \mathrm{~T}}$ is the total $\mathrm{S}_{4}$ measuring fluctuations due to any cause and $S_{4 N}$ is a measure of amplitude functions due to ambient noise described in more detail by Van Dierendonck and Hua, [2001] as:

$$
S_{4 N}=\sqrt{\frac{100}{\frac{S}{N_{o}}}\left[1+\frac{500}{19 \frac{S}{N_{o}}}\right]}
$$

where $S / N_{0}$ is the signal to noise ratio.

To obtain consistent statistics, following two criteria have been used in the present analysis: (a) in order to minimize the effects of the multipath on the observations, measurements with a satellite's elevation angle greater than $20 \mathrm{deg}$ are taken into account and (b) the analysis is limited to measurements made from satellites that are locked on for greater than 4 $\min (240 \mathrm{~s})$ to allow the GSV4004B receiver's de-trending filter to stabilize, as it has to be reinitialized whenever the lock to the carrier phase is lost. In this analysis only cases with $S_{4}>0.15$ are considered. Values of $S_{4}$ index between 0.15 and 0.5 are usually used for weak scintillations and $>0.5$ for strong scintillations [Hlubek et al. 2014]. IPPs (Ionospheric pierce points) 


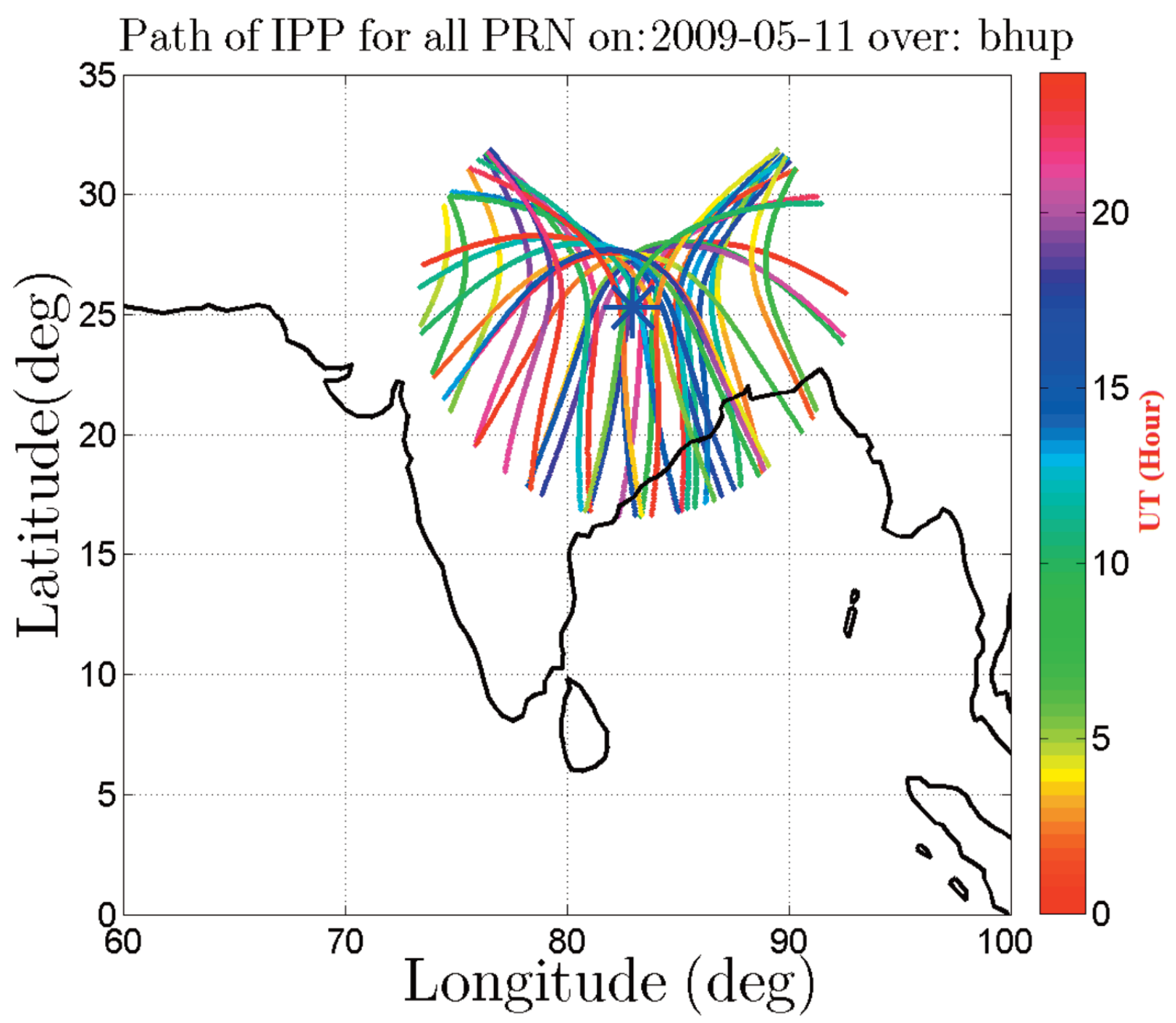

Figure 1. Map showing spatial coverage, in terms of IPP, of all GPS satellite with elevation greater than 20 deg observed from the GPS station installed at Varanasi (blue star) on 11 May 2009, a quiet day. Satellites have a coverage $17^{\circ}-32^{\circ} \mathrm{N}$ in latitude and $74^{\circ}-93^{\circ} \mathrm{E}$ in longitude.

geometry of all GPS satellites observed from Varanasi station is shown in Figure 1 for a typical day, the 29 February 2012. This figure shows that satellites have a good spatial coverage $17^{\circ}-32^{\circ} \mathrm{N}$ in latitude and $74^{\circ}$ $93^{\circ} \mathrm{E}$ in longitude.

To understand whether the occurrence of scintillations is affected by the solar activity, SSN (Sun Spot Number) and $\mathrm{F}_{10.7}$ (solar radio flux at $10.7 \mathrm{~cm}$ ) indices were considered. Corresponding values have been downloaded from websites: http:/ / sidc.be/silso/home and http://www.swpc.noaa.gov respectively.

To perform the analysis, a year is grouped into four seasons: March equinox (February to April), June solstice (May to July), September equinox (August to October) and December solstice (November to January). To study the diurnal, monthly, and seasonal occurrences only geomagnetic quiet days $(\mathrm{Kp} \leq 4)$ during the period from 2009 - 2014, have been considered for further analysis.

\section{Results and Discussion}

\subsection{Diurnal variation of scintillation occurrences}

The variation of hourly percentage occurrence of scintillation as a function of LT during 2009-2014 over Varanasi has been analyzed and shown in Figure 2. For a particular year, percentage diurnal occurrence of the scintillation during an hour interval of day has been computed against total number of scintillation occurrences observed during whole day (00:00-24:00 hour). Normally, scintillation occurrences are higher during nighttime hours (1930-0130 LT) than during daytime through over the years 2009-2014. Moreover, the occurrences show the maximum values during the years 2010 , 2011 and 2012. It can be easily seen in Figure 2 that the percentage occurrence of scintillation increases with solar activity. Apart from the nighttime scintillation occurrences, the daytime scintillation occurrences have also been observed all through the period 2009-2014 


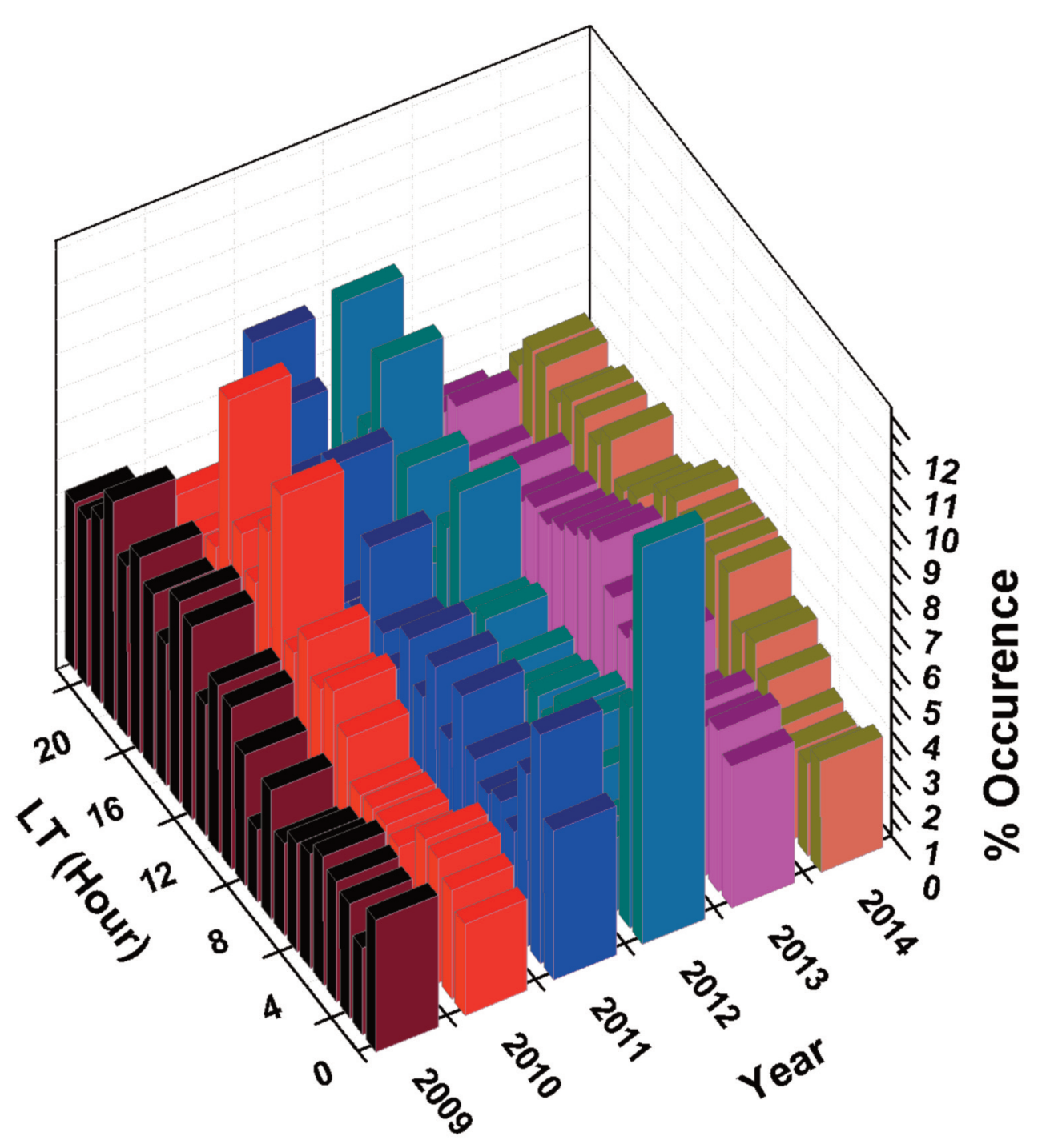

Figure 2. Diurnal percentage occurrences of amplitude scintillation (S4-index) against LT during the years 2009-2014.

with relatively small values as compared to nighttime. Similar diurnal occurrences of irregularities were reported by previous workers [Rama Rao et al. 2006, Nishioka et al. 2008, Singh et al. 2016, Kumar et al. 2016]. The development of post sunset irregularities is governed by mainly two parameters: evening F-layer drift as well as precursor gravity waves in seeding the instability. These two parameters further produce perturbations in density and polarization electric fields [Abdu 2012].

Daytime scintillations are expected to be caused by the irregularities associated with the sporadic E (Es) layers [Patel et al. 2009, Patra et al. 2012, Chatterjee and Chakraborty 2013, Alfonsi et al. 2013], whereas nighttime is associated with spread-F irregularities. Through statistical analysis, earlier studies focused on the existence of daytime irregularities depicted the favourable conditions for its occurrences to be: (a) at early morning, (b) at low-latitude, (c) at high altitude or (d) during geomagnetic storms. Generally, daytime
EPBs prefer higher altitude because of two factors: (i) daytime EPBs are leftover of nighttime/pre-sunrise (ii) EPBs at higher altitude are protected from the refilling due to daytime photo-ionization [Huang et al. 2013]. Li et al. [2011] have reported the diurnal occurrences of plasma bubbles. Their results show that during the June solstice months of low solar activity years, normally the majority of the EPBs are formed at post-midnight sector. However, these EPBs are mainly initiated by gravity wave perturbation at around the midnight and survive for several hours until the sunrise (or late in daytime).

\subsection{Seasonal occurrences}

Figure 3 shows $\mathrm{Pi}$ diagram of seasonal occurrences of scintillation during the years 2009-2014 over Varanasi. It is easily noticed that the occurrences are found to be minimum during solstice months. Scintillation occurrences are found to show equinoctial maximum throughout the years 2009-2014 only excluding the 


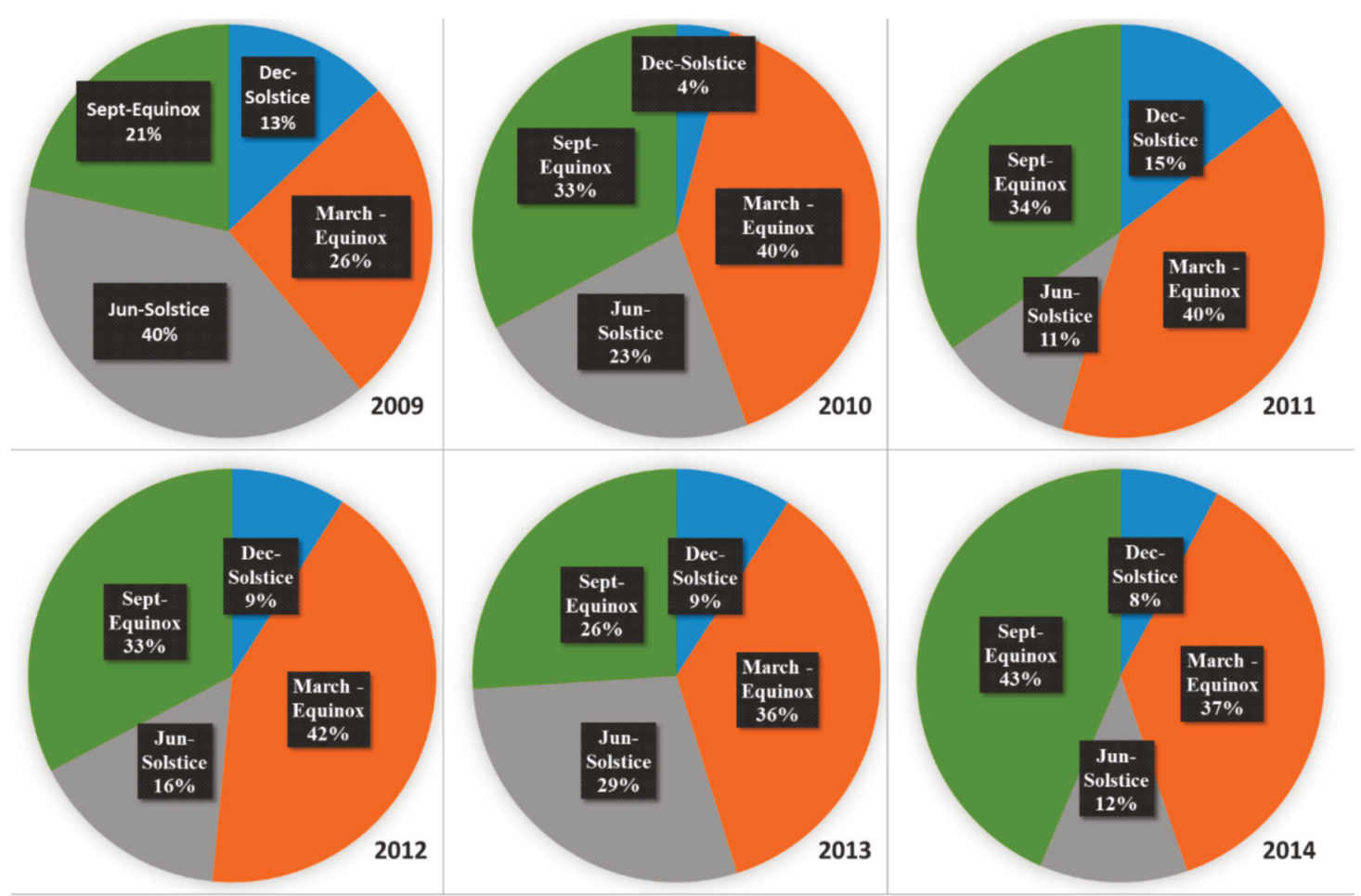

Figure 3. Pi diagram showing seasonal distribution of percentage scintillation occurrences during the years 2009-2014.

solar minimum year 2009. The seasonal maximum occurrences of ionospheric irregularities can be mainly controlled by two parameters: (i) one is post-sunset rise of F-layer (or vertical drift) due to pre-reversal enhancement (PRE) and (ii) other is seed perturbation in plasma density induced by gravity waves (GWs) which is originated from troposphere [Tsunoda 2010, Kumar et al. 2016, Kumar 2017]. During solar minimum period, the vertical drift due to PRE is less significant and seed perturbation can play significant role to manage the seasonal variation of ionospheric irregularities. Therefore GWs seed perturbation could be responsible for occurrences to be maximized during solstice months for solar minimum year 2009 [Tsunoda 2010].

In addition to seasonal maximum during equinox, scintillation occurrences also show equinoctial asymmetry throughout the years 2009-2014. The EPB occurrences may be affected by inter-hemispheric neutral winds (meridional winds) blowing from summer hemisphere to winter hemisphere. Using the numerical simulation, [Maruyama 1988] showed that the role of inter-hemispheric neutral winds, which is directed from summer hemisphere to winter hemisphere, is to increase the Pedersen conductivity and thereby reducing the growth rate of the R-T instability. This asymmetry is expected to arise by the difference in inter-hemispheric neutral winds strength during two equinoxes [Nishioka et al. 2008, Maruyama et al. 2009, Mungufeni et al. 2016,
Kumar et al. 2016]. The results reported over Indonesia indicated that, asymmetric meridional winds during vernal and autumn equinox periods over Indonesia may provide asymmetric growth of the irregularity and leading to the equinoctial asymmetry [Maruyama et al. 2009].

\subsection{Effect of solar activity}

To study the effect of solar activity on scintillation occurrences, $\mathrm{S}_{4}$ occurrences are plotted along with SSN and $\mathrm{F}_{10.7}$. Figure 4 shows seasonal scintillation occurrence number with SSN (in left panel) and with $\mathrm{F}_{10.7}$ (in right panel) over Varanasi during the years 2009-2014. Our analysis is divided into three seasons: summer (May, June, July, August), winter (Nov, Dec, Jan, Feb) and equinox (Mar, Apr, Sep, Oct). The scintillation trend is similar to that of solar activity indices (SSN and $\mathrm{F}_{10.7}$ ) throughout the years 2009-2014. Scintillation occurrences show highest values during the years 2013 and 2014. In contrast to this percentage diurnal occurrences show maximum values during 2010, 2011 and 2012 (Figure 2). To quantify the influence of solar activity on scintillations, a correlation analysis between scintillation occurrence numbers and solar indices has been made. Figure 5 shows the seasonal correlation between scintillation occurrence number and with both solar indices, $\mathrm{SSN}$ and $\mathrm{F}_{10.7}$, during the years 2009-2014. The correlation between two parameters is 


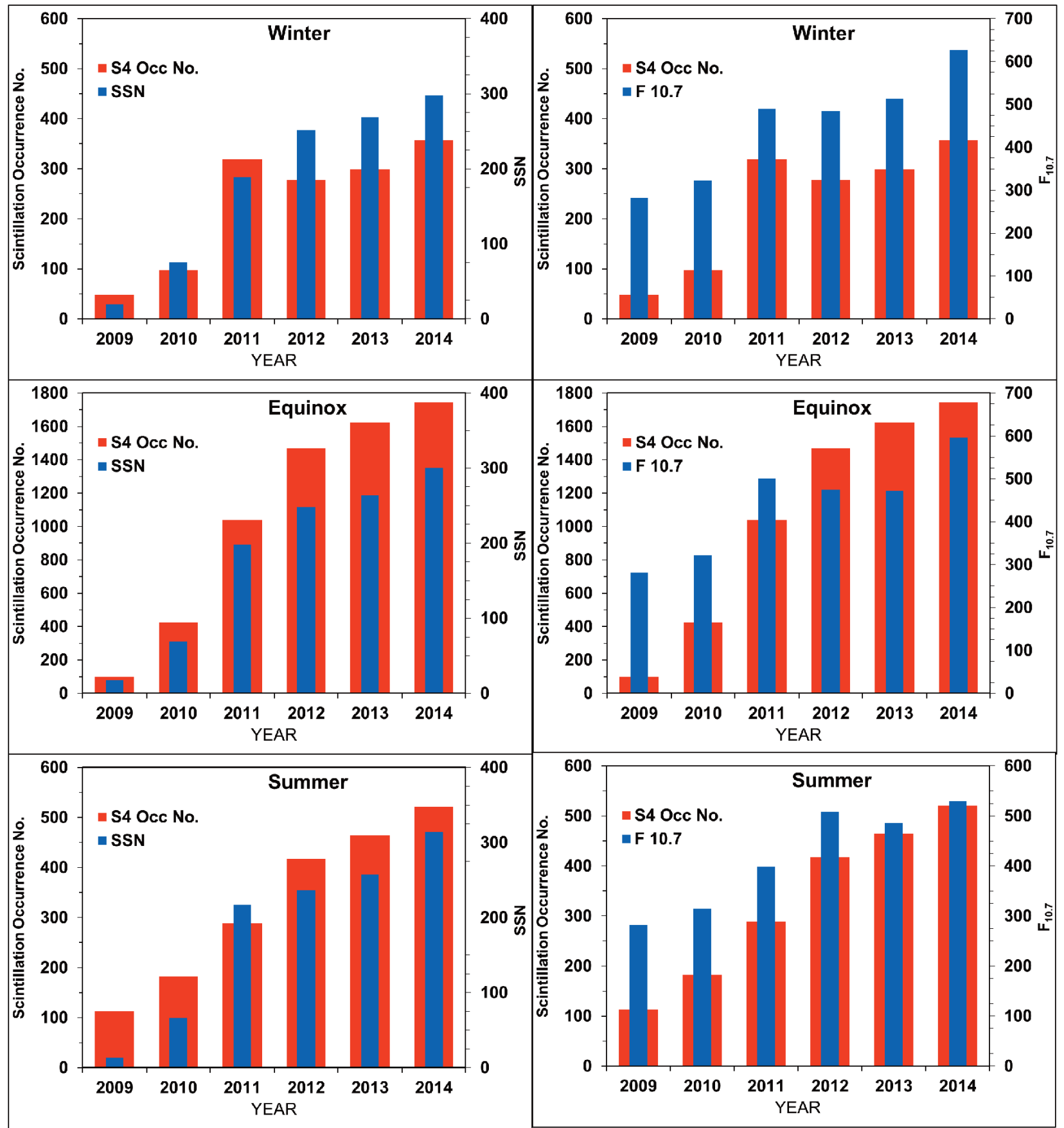

Figure 4. Seasonal scintillation occurrence number with SSN in left panel and with F10.7 in right panel for the years 2009-2014.

found to be more than 0.90 during all seasons, which indicates the influence of solar activity. Correlations are also seasonal dependent which is maximum during the equinox with SSN $\left(\mathrm{R}^{2}=0.99\right)$ and during summer with $\mathrm{F}_{10.7}\left(\mathrm{R}^{2}=0.96\right)$. Figure 6 shows annual total scintillation occurrence number along with the SSN (left-top) and the $\mathrm{F}_{10.7}$ (right-top) annual means. Corresponding correlation analyses are shown in the bottom panels. Annual scintillation occurrences are also found to vary linearly in accordance with solar activity with annual correlation $\left(\mathrm{R}^{2}=0.97\right)$ with $\mathrm{SSN}$ and $\left(\mathrm{R}^{2}=0.95\right)$ with $\mathrm{F}_{10.7}$. Annual occurrences are also maximum during the high sunspot year 2014 and minimum during low sunspot year 2009 .

The solar activity plays an important role in scintillation/irregularities occurrences and more irregularities can be produced during the solar maximum years as compared to solar minimum years [Basu 2002]. Large scintillation occurrences have been observed during high solar activity and least during low solar activity years (Figures 5,6). The evening equatorial upward plasma drift due to PRE is an important factor controlling the scintillation/EPB occurrences which varies with solar activity. Specifically, higher scintillation occurrences could be expected during high solar ac- 

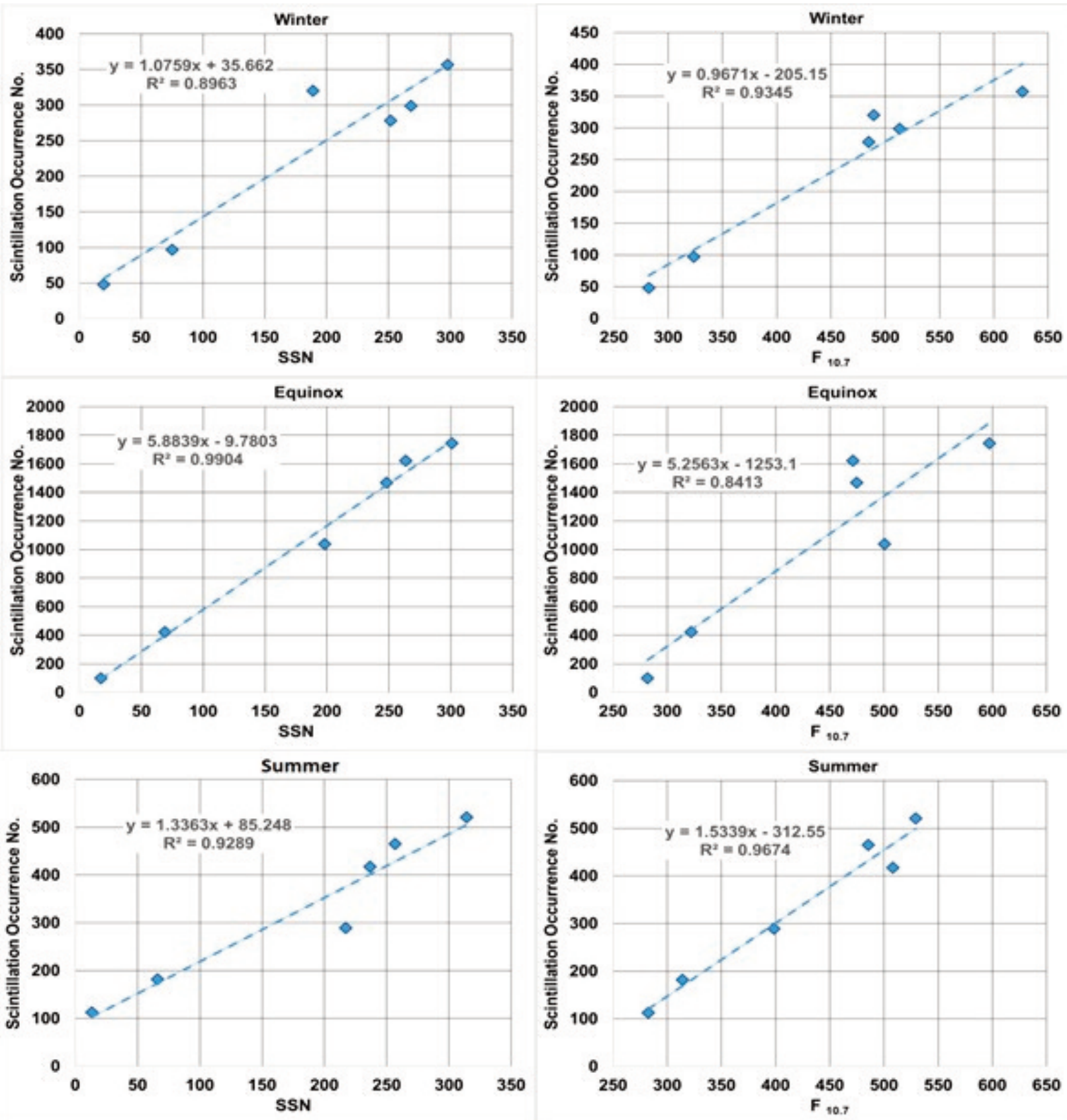

Figure 5. Seasonal correlation analysis between the scintillation occurrence number with SSN (left) and between the scintillation occurence and F10.7 (right), for the years 2009-2014.

tivity year as compared to that during low solar activity year. In support of this, using both the observation and model data, Vichare et al. [2005] and Fejer et al. [2008] have shown a linear correlation between evening equatorial upward plasma drift and solar flux level. Furthermore, Stolle et al. [2008] and Su et al. [2008] have presented global confirmation for the linear relationship between the EPB occurrences rate and the vertical plasma drift. Recently using the data from GPS based measurements, Tariku [2015] have shown that evening equatorial upward plasma drift is more prominent during the high solar activity years and almost absent during the solar minimum period.

Using network of GPS data, Nishioka et al. [2008] have shown that the influence of solar activity on irregularities / EPB occurrences depends on longitude. They reported highest correlation for African-Asian sector and a poor correlation for Atlantic sector. Their results for Atlantic sector, is in contrast to our results observed over EIA region Varanasi, India. Previous studies reported that the influences of solar activity on irregularities occurrences are further complicated by observation techniques which can cause conflicting interpretation of the irregularities climatology [Miller et al. 2010, Makela and Miller 2011]. Therefore, to resolve this issue further studies comparing solar activity influences on irregularities from different techniques are further required. 


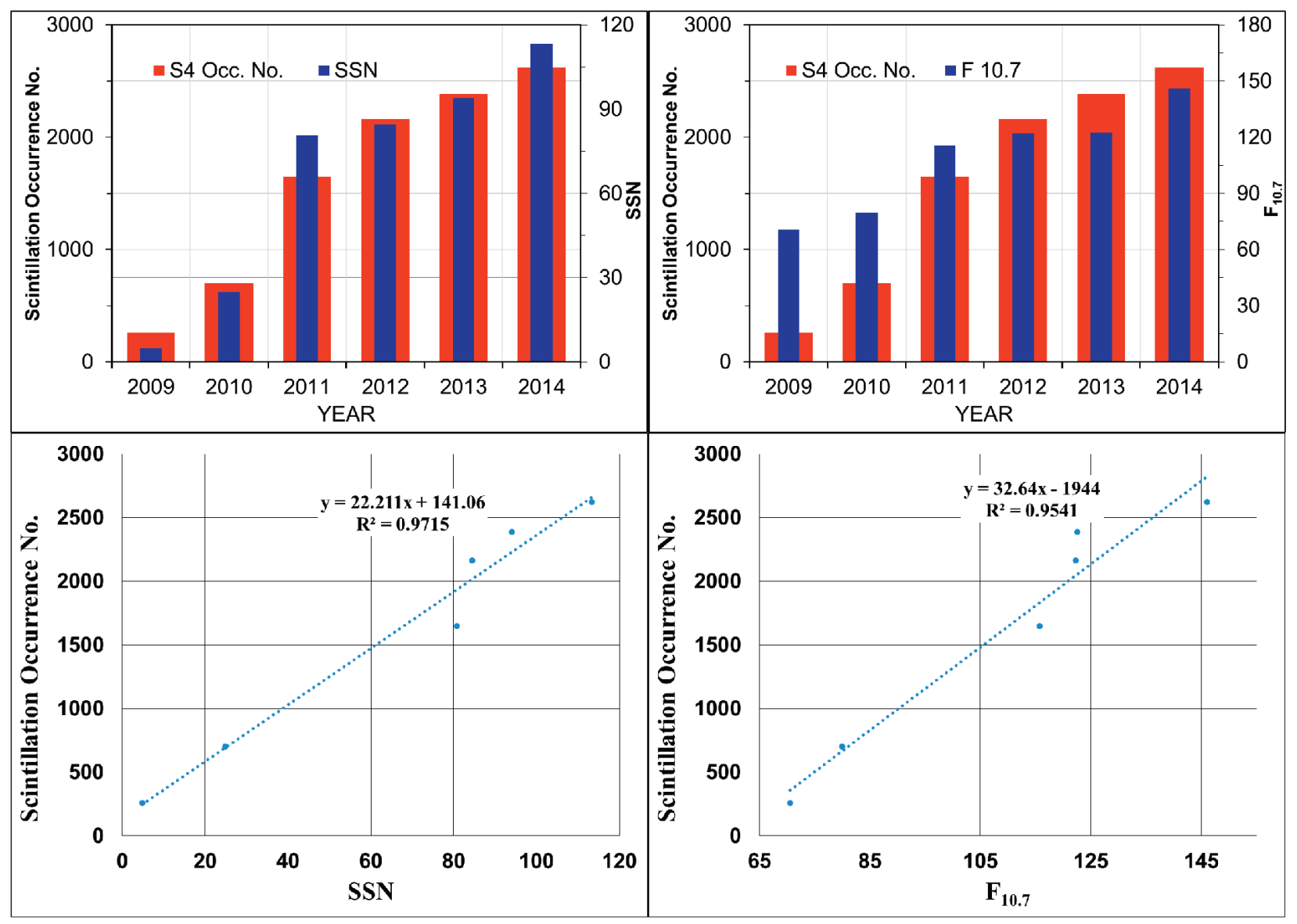

Figure 6. Annual total scintillation occurrence number along with the annual mean SSN (left-top) and of F10.7 cm flux (right-top), from 2009 to 2014. Corresponding correlation analyses are shown in the bottom panels.

\section{Conclusions}

In this study, the value of $S_{4}$ index greater than 0.15 is taken as a scintillation occurrence indicator. Observation data from ground station, Varanasi (India) is used to study the trend of scintillation occurrence during the years 2009-2014. Some features of scintillation occurrences are observed as follows:

- The scintillation occurrences are found to be more probable during nighttime hours (1930$0130 \mathrm{LT})$. In addition to nighttime, daytime scintillations were also observed with relatively smaller probability.

- Scintillation occurrences are found to show equinoctial maximum throughout the years 20092014 with the exception of the solar minimum year 2009. Gravity wave seed perturbation from lower atmosphere and pre-reversal enhancement in zonal electric field are basically two parameters to control the seasonal variations in scintillations/irregularities. During solar minimum year 2009 unusual seasonal maximum could be attributed to a predominance of gravity wave seed perturbation over pre-reversal enhancement in zonal electric field, which makes scintillations occurrences maximum during solstice months instead of equinox.

- The equinoctial asymmetry in scintillation occurrences has been observed throughout the years 2009-2014. The equinoctial asymmetry in scintillation could be caused by inter-hemispheric neutral wind which is blowing from summer to winter hemisphere [Maruyama et al. 2009].

- The influence of solar activity on scintillation occurrence has been studied by quantifying correlations with SSN and $\mathrm{F}_{10.7}$ which are found to be different in different seasons, with a maximum in the equinox season with SSN and in summer season with $\mathrm{F}_{10.7}$. The results agree with those previously found for the Africa-Asian sector, but they are different than those previously found for the Atlantic sector [Nishioka et al. 2008].

Acknowledgment. Authors would like to express their gratitude to NOAA (website: http: / / www.swpc.noaa.gov) for $\mathrm{F}_{10.7}$ and SSN (Sun Spot Number) data. This work is partially supported by ISRO (Indian Space Research Organization), Bangalore under 
ISRO-SSPS to BHU. Vishnu S. Rathore is thankful to UGC to provide fellowship. SK is thankful to SREB/DST New Delhi, for providing financial assistance under FASTRACK (SR/FTP/ES-164/2014). Authors thank the reviewer for his valuable comments/suggestions which helped to improve the MS quality.

\section{References}

Aarons, J. (1982). Global Morphology of Ionospheric Scintillations, Proc. IEEE 70, 360-378 doi:10.1109/PROC.1982.12314.

Aarons, J. (1993). The longitudinal morphology of equatorial F-layer irregularities relevant to their occurrence, Space Sci. Rev. 63, 209-243 doi:10.1007/BF00750769.

Aarons, J., Mullen, J. P., Koster, J. P., DaSilva, R. F., Medeiros, J. R., Medeiros, R. T., Bushby, A., Pantoja, J., Lanat, J., \& Paulson, M. R. (1980). Seasonal and geomagnetic control of equatorial scintillations in two longitudinal sectors, J. Atmos. Terr. Phys. 42, 861-866 doi:10.1016/0021-9169(80)90090-2.

Abdu, M. A. (2001). Outstanding problems in the equatorial ionosphere-thermosphere electrodynamics relevant to spread F, J. Atmos. Solar-Terrestrial Phys. 63, 869-884 doi:10.1016/S1364-6826(00)00201-7.

Abdu, M. A. (2012). Equatorial spread F/plasma bubble irregularities under storm time disturbance electric fields, J. Atmos. Solar-Terrestrial Phys. 75-76, 44-56 doi:10.1016/j.jastp.2011.04.024.

Alfonsi, L., Spogli, L., Tong, J. R., De Franceschi, G., Romano, V., Bourdillon, A., Le Huy, M., \& Mitchell, C. N. (2011). GPS scintillation and TEC gradients at equatorial latitudes in April 2006, Adv. Sp. Res. 47, 1750-1757 doi:10.1016/j.asr.2010.04.020.

Alfonsi, L., Spogli, L., Pezzopane, M., Romano, V., Zuccheretti, E., De Franceschi, G., Cabrera, M.A., Ezquer, R.G. (2013). Comparative analysis of spread-F signature and GPS scintillation occurrences at Tucumán, Argentina. J. Geophys. Res. Sp. Phys. 118, 4483-4502. doi:10.1002/jgra.50378

Basu, B. (2002). On the linear theory of equatorial plasma instability: Comparison of different descriptions, J. Geophys. Res. Sp. Phys. 107, SIA 18-1-SIA 18 10 doi:10.1029/2001JA000317.

Basu, S., \& Basu, S. (1985). Equatorial scintillations: advances since ISEA-6, J. Atmos. Terr. Phys. 47, 753768 doi:10.1016/0021-9169(85)90052-2.

Béniguel, Y., Adam, J. P., Jakowski, N., Noack, T., Wilken, V., Valette, J. J., Cueto, M., Bourdillon, A., Lassudrie-Duchesne, P., \& Arbesser-Rastburg, B. (2009). Analysis of scintillation recorded during the PRIS measurement campaign, Radio Sci. 44
doi:10.1029/2008RS004090.

Béniguel, Y., Forte, B., Radicella, S. M., Strangeways, H. J., Gherm, V. E., \& Zernov, N. N. (2004). Scintillations effects on satellite to Earth links for telecommunication and navigation purposes, Ann. Geophys. 47, 1179-1199 doi:10.4401/ag-3293.

Brahmanandam, P. S., Uma, G., Liu, J. Y., Chu, Y. H., Devi, N. S. M. P. L., \& Kakinami, Y. (2012). Global S4 index variations observed using FORMOSAT-3/ COSMIC GPS RO technique during a solar minimum year, J. Geophys. Res. Sp. Phys. 117, 1-31 doi:10.1029/2012JA017966.

Carter, B. A., Zhang, K., Norman, R., Kumar, V. V., \& Kumar, S. (2013). On the occurrence of equatorial F-region irregularities during solar minimum using radio occultation measurements, J. Geophys. Res. Sp. Phys. 118, 892-904 doi:10.1002/jgra.50089.

Chatterjee, S., \& Chakraborty, S. K. (2013). Variability of ionospheric scintillation near the equatorial anomaly crest of the Indian zone, Ann. Geophys. 31, 697-711 doi:10.5194/angeo-31-697-2013.

Deng, B., Huang, J., Liu, W., Xu, J., \& Huang, L. (2013). GPS scintillation and TEC depletion near the northern crest of equatorial anomaly over South China, Adv. Sp. Res. 51, 356-365 doi:10.1016/j.asr.2012.09.008.

Fejer, B. G., Jensen, J. W., \& Su, S. Y. (2008). Seasonal and longitudinal dependence of equatorial disturbance vertical plasma drifts, Geophys. Res. Lett. 35, L20106 doi:10.1029/2008GL035584.

Groves, K. M., Basu, S., Weber, E. J., Smitham, M., Kuenzler, H., Valladares, C. E., Sheehan, R., MacKenzie, E., Secan, J. a., Ning, P., McNeill, W. J., Moonan, D. W., \& Kendra, M. J. (1997). Equatorial scintillation and systems support, Radio Sci. 32, 2047 doi:10.1029/97RS00836.

Haerendel, G. (1973). Theory of Equatorial Spread F, Phys., Garching, Ger.

Hlubek, N., Berdermann, J., Wilken, V., Gewies, S., Jakowski, N., Wassaie, M., \& Damtie, B. (2014). Scintillations of the GPS, GLONASS, and Galileo signals at equatorial latitude, J. Sp. Weather Sp. Clim. 4, A22 doi:10.1051/swsc/2014020.

Huang, L., Huang, J., Wang, J., Jiang, Y., Deng, B., Zhao, K., \& Lin, G. (2013). Analysis of the north-south asymmetry of the equatorial ionization anomaly around $110^{\circ} \mathrm{E}$ longitude, J. Atmos. Solar-Terrestrial Phys. 102, 354-361 doi:10.1016/j.jastp.2013.06.010.

Huang, C. S., De La Beaujardiere, O., Roddy, P. A., Hunton, D. E., Pfaff, R. F., Valladares, C. E., \& Ballenthin, J. O. (2011). Evolution of equatorial ionospheric plasma bubbles and formation of broad plasma depletions measured by the C/NOFS satel- 
lite during deep solar minimum, J. Geophys. Res. Sp. Phys. 116 doi:10.1029/2010JA015982.

Iyer, K. N., Souza, J. R., Pathan, B. M., Abdu, M. A., Jivani, M. N., \& Joshi, H. P. (2006). A model of equatorial and low latitude VHF scintillation in India, Indian J. Radio Sp. Phys. 35, 98-104.

Jiao, Y., Morton, Y., \& Taylor, S. (2014). Comparative studies of high-latitude and equatorial ionospheric scintillation characteristics of GPS signals.Pages 3742 in 2014 IEEE/ION Position, Location and Navigation Symposium - PLANS 2014. IEEE.

Kintner, P. M., Ledvina, B. M., de Paula, E. R., \& Kantor, I. J. (2004). Size, shape, orientation, speed, and duration of GPS equatorial anomaly scintillations, Radio Sci. 39 doi:10.1029/2003RS002878.

Kumar, S., Chen, W., Liu, Z., \& Ji, S. (2016). Effects of solar and geomagnetic activity on the occurrence of equatorial plasma bubbles over Hong Kong, J. Geophys. Res. Sp. Phys. 121, 9164-9178 doi:10.1002/2016JA022873.

Kumar, S. (2017). Morphology of equatorial plasma bubbles during low and high solar activity years over Indian sector, J. Astrophys \& Space Sci., 362,93.

Li, G., Ning, B., Abdu, M. A., Yue, X., Liu, L., Wan, W., $\& \mathrm{Hu}, \mathrm{L}$. (2011). On the occurrence of postmidnight equatorial F region irregularities during the June solstice, J. Geophys. Res. Sp. Phys. 116, n/a-n/a doi:10.1029/2010JA016056.

Li, G., Ning, B., \& Yuan, H. (2007). Analysis of ionospheric scintillation spectra and TEC in the Chinese low latitude region, Earth, Planets Sp. 59, 279-285 doi:10.1186/BF03353105.

Makela, J. J., \& Miller, E. S. (2011). Influences on the Development of Equatorial Plasma Bubbles: Insights from a Long-Term Optical Dataset BT - Aeronomy of the Earth's Atmosphere and Ionosphere.Pages 239-249 in Aeronomy of the Earth's Atmosphere and Ionosphere. Springer Netherlands, Dordrecht.

Maruyama, T. (1988). A diagnostic model for equatorial spread F: 1. Model description and application to electric field and neutral wind effects, J. Geophys. Res. 93, 14611-14622 doi:10.1029/JA093iA12p14611.

Maruyama, T., \& Matuura, N. (1984). Longitudinal variability of annual changes in activity of equatorial spread F and plasma bubbles, J. Geophys. Res. 89, 10903 doi:10.1029/JA089iA12p10903.

Maruyama, T., Saito, S., Kawamura, M., Nozaki, K., Krall, J., \& Huba, J. D. (2009). Equinoctial asymmetry of a low-latitude ionosphere-thermosphere system and equatorial irregularities: Evidence for meridional wind control, Ann. Geophys. 27, 20272034 doi:10.5194/ angeo-27-2027-2009.
Mendillo, M., \& Baumgardner, J. (1982). Airglow Characteristics of Equatorial Plasma Depletions, J. Geophys. Res. 87, 7641-7652 doi:10.1029/JA087iA09p07641.

Miller, E. S., Makela, J. J., Groves, K. M., Kelley, M. C., \& Tsunoda, R. T. (2010). Coordinated study of coherent radar backscatter and optical airglow depletions in the central Pacific, J. Geophys. Res. Sp. Phys. 115 doi:10.1029/2009JA014946.

Muella, M. T. A. H., de Paula, E. R., Kantor, I. J., Rezende, L. F. C., \& Smorigo, P. F. (2009). Occurrence and zonal drifts of small-scale ionospheric irregularities over an equatorial station during solar maximum - Magnetic quiet and disturbed conditions, Adv. Sp. Res. 43, 1957-1973 doi:10.1016/j.asr.2009.03.017.

Mungufeni, P., Habarulema, J. B., \& Jurua, E. (2016). Trends of ionospheric irregularities over African low latitude region during quiet geomagnetic conditions, J. Atmos. Solar-Terrestrial Phys. 138-139, 261-267 doi:10.1016/j.jastp.2016.01.015.

Nishioka, M., Saito, A., \& Tsugawa, T. (2008). Occurrence characteristics of plasma bubble derived from global ground-based GPS receiver networks, J. Geophys. Res. Sp. Phys. 113 doi:10.1029/2007JA012605.

Oron, S., D’ujanga, F. M., \& Ssenyonga, T. J. (2013). Ionospheric tec variations during the ascending solar activity phase at an equatorial station, Uganda, Indian J. Radio Sp. Phys. 42, 7-17.

Patel, K., Singh, A. K., Patel, R. P., \& Singh, R. P. (2009). Characteristics of low latitude ionospheric E-region irregularities linked with daytime VHF scintillations measured from Varanasi, J. Earth Syst. Sci. 118, 721732 doi:10.1007/s12040-009-0058-x.

Patra, A. K., Chaitanya, P. P., \& Bhattacharyya, A. (2012). On the nature of radar backscatter and $250 \mathrm{MHz}$ scintillation linked with an intense daytime E s patch, J. Geophys. Res. Sp. Phys. 117 doi:10.1029/2011JA016981.

Rama Rao, P. V. S., Gopi Krishna, S., Niranjan, K., \& Prasad, D. S. V. V. D. (2006). Study of spatial and temporal characteristics of L-band scintillations over the Indian low-latitude region and their possible effects on GPS navigation, Ann. Geophys. 24, 1567-1580 doi:10.5194/ angeo-24-1567-2006.

Rastogi, R. G. (1980). Seasonal and solar-cycle variations of equatorial spread-F in the American zone, J. Atmos. Terr. Phys. 42, 593-597 doi:10.1016/00219169(80)90093-8.

Seemala, G. K., \& Valladares, C. E. (2011). Statistics of total electron content depletions observed over the South American continent for the year 2008, Radio 
Sci. doi:10.1029/2011RS004722.

Seif, A., Abdullah, M., Hasbi, A. M., \& Zou, Y. (2012). Investigation of ionospheric scintillation at UKM station, Malaysia during low solar activity, Acta Astronaut. 81, 92-101 doi:10.1016/j.actaastro.2012.06.024.

Singh, R. P., Patel, R. P., \& Singh, A. K. (2004). Effect of solar and magnetic activity on VHF scintillations near the equatorial anomaly crest, Ann. Geophys. 22, 2849-2860 doi:10.5194/angeo-22-2849-2004.

Singh, A. K., Patel, R. P., \& Singh, R. P. (2006). Statistical features of overhead ionospheric irregularities and its generation mechanism at low-latitude, J. Atmos. Solar-Terrestrial Phys. 68, 1116-1124 doi:10.1016/j.jastp.2006.02.002.

Singh, S. B., Rathore, V. S., Singh, A. K., \& Singh, A. K. (2016). Ionospheric irregularities at low-latitude using VHF scintillations during extreme low solar activity period (2008-2010), Acta Geod. Geophys. 52, 35-51 doi:10.1007/s40328-016-0168-2.

Spogli, L., Alfonsi, L., De Franceschi, G., Romano, V., Aquino, M. H. O., \& Dodson, A. (2009). Climatology of GPS ionospheric scintillations over high and mid-latitude European regions, Ann. Geophys. 27, 3429-3437 doi:10.5194/angeo-27-3429-2009.

Spogli, L., Cesaroni, C., Di Mauro, D., Pezzopane, M., Alfonsi, L., Musicò, E., Povero, G., Pini, M., Dovis, F., Romero, R., Linty, N., Abadi, P., Nuraeni, F., Husin, A., Le Huy, M., Lan, T.T., La, T.V., Pillat, V.G., Floury, N., (2016). Formation of ionospheric irregularities over Southeast Asia during the 2015 St. Patrick’s Day storm. J. Geophys. Res. Sp. Phys. 121, 12,211-12,233. doi:10.1002/2016JA023222

Stolle, C., Lühr, H., \& Fejer, B. G. (2008). Relation between the occurrence rate of ESF and the equatorial vertical plasma drift velocity at sunset derived from global observations, Ann. Geophys. 26, 39793988 doi:10.5194/ angeo-26-3979-2008.

Straus, P. R., Anderson, P. C., \& Danaher, J. E. (2003). GPS occultation sensor observations of ionospheric scintillation, Geophys. Res. Lett. 30, 1-4 doi:10.1029/2002GL016503.

Su, S.-Y., Chao, C. K., \& Liu, C. H. (2008). On monthly/seasonal/longitudinal variations of equatorial irregularity occurrences and their relationship with the postsunset vertical drift velocities, J. Geophys. Res. Sp. Phys. 113, n/a-n/a doi:10.1029/2007JA012809.

Tanna, H. J. J., Karia, S. P. P., \& Pathak, K. N. N. (2013). A study of $\mathrm{L}$ band scintillations during the initial phase of rising solar activity at an Indian low latitude station, Adv. Sp. Res. 52, 412-421 doi:10.1016/j.asr.2013.03.022.

Tariku, Y. (2015). Patterns of GPS-TEC variation over low-latitude regions (African sector) during the deep solar minimum (2008 to 2009) and solar maximum (2012 to 2013) phases, Earth, Planets Sp. 67, 35 doi:10.1186/s40623-015-0206-2.

Tsunoda, R. T. (2010). On equatorial spread F: Establishing a seeding hypothesis, J. Geophys. Res. Sp. Phys. 115 doi:10.1029/2010JA015564.

Van. Dierendonck, A. J., \& Hua, Q. (2001). Measuring Ionospheric Scintiallation Effects from GPS Signals, ION 57th Annu. Meet., 391-396.

Vichare, G., Alex, S., \& Lakhina, G. S. (2005). Some characteristics of intense geomagnetic storms and their energy budget, J. Geophys. Res. Sp. Phys. 110, A03204 doi:10.1029/2004JA010418.

\footnotetext{
${ }^{*}$ Corresponding author: Abhay Kumar Singh, Department of Physics, Institute of Science, Banaras Hindu University, Varanasi, India; email: singhak@bhu.ac.in.

(C) 2018 by the Istituto Nazionale di Geofisica e Vulcanologia. All rights reserved.
} 